\title{
'Ourania' Walnut
}

\section{Ioannis Manthos and Dimos Rouskas \\ Department of Nut Trees, Institute of Plant Breeding and Genetic Resources, Hellenic Agricultural Organization, Dimitra, Greece}

Additional index words. description, Greece, Juglans regia, lateral bearing

In the Department of Nut Trees of the Hellenic Agricultural Organization (HAO)Dimitra, a significant effort has been made, from 1985 until today, to create new, remarkable walnut varieties with high productivity and good fruit quality that are suitable for the soil and climatic conditions of Greece. Through these endeavors and specific crosses, a lateral-bearing cultivar has emerged with satisfactory characteristics: 'Ourania'. This is a new walnut (Juglans regia) cultivar of Greek origin created by a cross between 'Hartley' and 'Gustine'. It is a mid-to-late cultivar, with pomological characteristics similar to 'Hartley', but it presents a high, lateral bearing habit. It is a walnut cultivar of high importance not only for the region of Greece, but also for other countries. It is suitable for cultivation in semimountainous and mountainous areas, where the last spring frost occurs in mid-April.

\section{Origin}

'Ourania' is a new walnut cultivar, a cross between 'Hartley' (maternal parent) and 'Gustine' (paternal parent). The cross was made in 1993 at the Department of Nut Trees of the Institute of Plant Breeding and Genetic Resources of HAO-Dimitra by researcher Dimos Rouskas. 'Hartley' was selected because of its high productivity, although it presents a low (5\% to $10 \%)$ lateral bearing habit, whereas 'Gustine' was selected because of its high, fruitful lateral bearing habit $(85 \%$ to $90 \%)$. The objective of our research is to provide information about the new lateral cultivar Ourania and to evaluate it in comparison with 'Chandler', the top-selling walnut cultivar, and its high-yielding paternal 'Hartley', in regard to its pomological and phenological characteristics.

\section{Method}

The study was carried out at the Department of Nut Trees in Lamia, Fthiotida, Greece (lat. $38^{\circ} 49^{\prime} 36^{\prime \prime} \mathrm{N}$; long. $22^{\circ} 26^{\prime} 27^{\prime \prime} \mathrm{E}$; eleva-

\footnotetext{
Received for publication 7 Dec. 2020. Accepted for publication 25 Jan. 2021.

Published online 26 February 2021.

I.M. is the corresponding author. E-mail: manthosjo@ yahoo.gr.

This is an open access article distributed under the CC BY-NC-ND license (https://creativecommons. org/licenses/by-nc-nd/4.0/).
}

tion, $15 \mathrm{~m}$; slope, $\approx 1 \%$ ). The experimental orchard was planted on clayey soil (clay, $52 \%$ to $56 \%$; silt, $32 \%$ to $36 \%$; sand, $8 \%$ to $14 \%$ ). All cultivars studied are kept in collections at the department for systemic evaluation. Phenological and pomological traits (Tables 1 and 2) of the cultivars included in the trial were collected between 2010 and 2019, and were evaluated according to the International Plant Genetic Resources Institute (1994) and the International Union for the Protection of New Varieties of Plants (1999) criteria. 'Chandler' and 'Hartley' established in the same collections of the Department of Nut Trees were included in the trial as reference cultivars.

\section{Description}

Phenological evaluation. 'Ourania' is a high-yield cultivar when it comes to full production at 9 years of age, with an estimated yield of $29.00 \mathrm{~kg} /$ tree. This cultivar presents $80 \%$ lateral bearing habit, whereas that of its maternal 'Hartley' has been found to be $5 \%$ to $10 \%$, and its paternal 'Gustine', $85 \%$ to $90 \%$. 'Ourania' trees present intermediate vigor, a semierect growth habit, and dense branching, similar to 'Chandler' and 'Hartley' (Table 1). Budbreak occurs on 6 Apr. $\pm 8.22 \mathrm{~d}$, depending on climatic conditions, at the same date as 'Chandler' and $1 \mathrm{~d}$ earlier than 'Hartley'. Its first female flowers bloom on 24 Apr. $\pm 6.15 \mathrm{~d}, 3 \mathrm{~d}$ and $1 \mathrm{~d}$ earlier than 'Chandler' and 'Hartley', respectively. The last female flowers bloom on 6 May $\pm 4.76 \mathrm{~d}, 3 \mathrm{~d}$ earlier than 'Chandler' and on the same date as 'Hartley'. The first male-flower bloom date is the same as 'Chandler' (18 Apr. $\pm 7.82 \mathrm{~d}$ ) and $1 \mathrm{~d}$ later than 'Hartley'. The last male-flower bloom date occurs on 28 Apr. $\pm 5.66 \mathrm{~d}$, the same date as 'Hartley' and $1 \mathrm{~d}$ earlier than 'Chandler'. Harvest of nuts occurs $\approx 29$ Sept., similar to 'Hartley', and $4 \mathrm{~d}$ earlier than 'Chandler' (Table 1). Flowering of 'Ourania' is protandrous, with the first catkins appearing at 4 years and the first female flowers appearing at 1 year. It presents easy hull dehiscence (similar to 'Chandler' and 'Hartley') low sunburn susceptibility of the hull, intermediate susceptibility to the codling moth (Cydia pomonella L.), and a very low susceptibility to walnut blight (Xanthomonas campestris) (Table 1).

Pomological traits. Fruit characteristics are presented in Table 2 and were collected over 10 consecutive years. Measurements concerning nut dimensions and weights are presented as mean \pm SD. The 'Ourania' nut has a medium size and a triangular shape, similar to 'Hartley'. The shell texture is rough and light in color, with intermediate shell integrity. The nut shape in a longitudinal section through the suture and in a longitudinal section perpendicular to suture is triangular. The shape in cross-section is oblate; the shape of the base perpendicular to the suture is truncate. The shape of the apex perpendicular to the suture is pointed; the prominence of the apical tip is medium. The position of the pad on the suture is found on the upper two-thirds of the nut, the prominence of the pad on the suture is strong, the width of the pad is broad, and the depth of the groove along the pad on the suture is medium. The structure of the surface of the 'Ourania' nutshell is slightly grooved. Nuts present medium adherence of the two halves of shell, and a thin thickness of primary and secondary membranes. All these nut characteristics are the same as those for 'Hartley' nuts, except for the prominence of the apical tip and the depth of the groove along the pad on the suture, which differ. Most of these characteristics differ from those of 'Chandler', as shown in Table 2. The mean weight of the 'Ourania' nut in the shell is $14.38 \pm$ $0.77 \mathrm{~g}$, the mean kernel weight is $6.43 \pm 0.36$ $\mathrm{g}$, and the mean kernel percentage is $44.74 \%$ $\pm 2.14 \%$. Although 'Ourania' in-shell nuts are heavier than the reference cultivars, the percentage of the kernel is less than that of 'Chandler'. 'Ourania' nuts have a light kernel color, with well kernel fill and easy removal of the kernel halves, similar to 'Hartley' nuts (Table 2; Supplemental Fig. 1).

In conclusion, the new cross-bred walnut cultivar Ourania combines the high yield and good nut traits of 'Hartley' with the high lateral bearing habit of 'Gustine'. Its phenological characteristics reveal that it is suitable for the climatic conditions of Greece, in mountainous areas, and even more in lowland areas of North Greece. Its nut traits are comparable to that of one of the top walnut cultivars (Chandler), making it a promising cultivar not only for Greece, but also for other regions with similar climatic conditions.

\section{Availability}

'Ourania' has not yet been registered in the official list of the Greek Ministry of Agriculture, but this is expected in the near future.

\section{Literature Cited}

International Plant Genetic Resources Institute. 1994. Descriptors for walnut (Juglans spp.). International Plant Genetic Resources Institute, Rome, Italy.

International Union for the Protection of New Varieties of Plants. 1999. Guidelines for the conduct of tests for distinctness, uniformity and stability. Walnut (Juglans regia L.). UPOV-TG/125/6. International Union for the Protection of New Varieties of Plants, Geneva, Switzerland. 
Table 1. Average phenological characteristics of 'Ourania' walnut compared with the reference cultivars Chandler and Hartley.

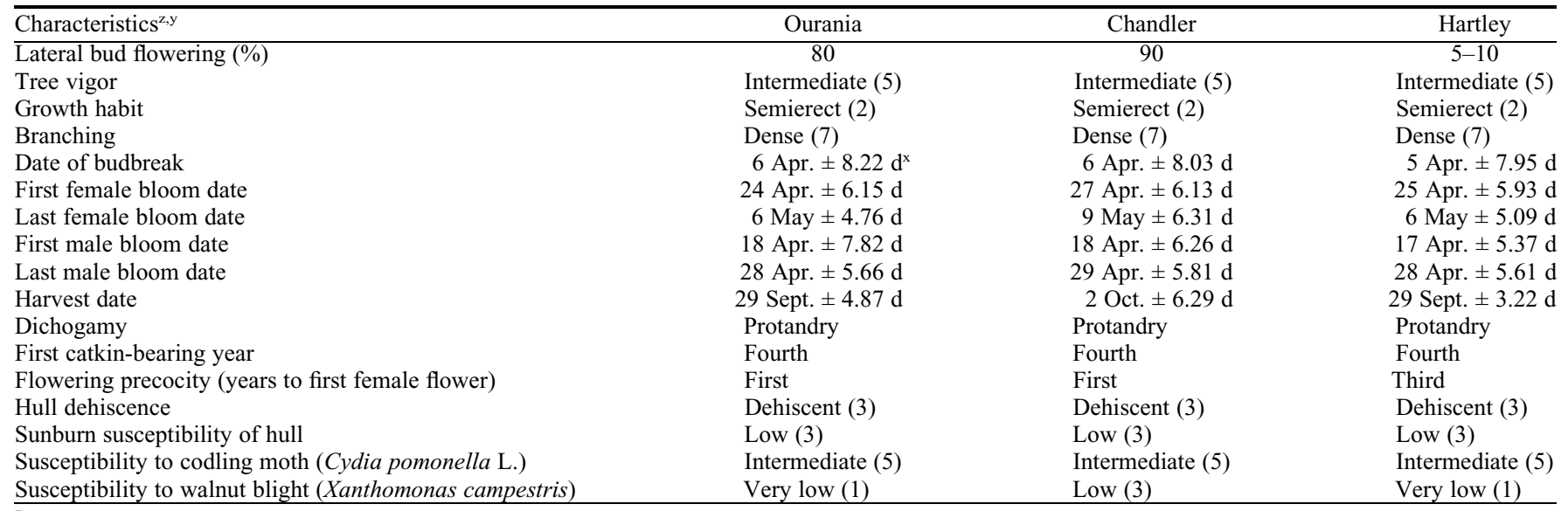

${ }^{\mathrm{z}}$ According to the International Plant Genetic Resources Institute (1994) descriptors for walnut.

${ }^{\mathrm{y}}$ When given, numbers in parenthesis refer to the respective description according to the International Plant Genetic Resources Institute (1994).

${ }^{\mathrm{x}}$ Data are presented as date $\pm \mathrm{SD}$.

Table 2. Average nut and kernel traits of 'Ourania' walnut compared with the reference cultivars Chandler and Hartley.

\begin{tabular}{|c|c|c|c|}
\hline Characteristics & Ourania & Chandler & Hartley \\
\hline Nut size $^{z}$ & Medium (5) & Medium (5) & Medium (5) \\
\hline Nut height $(\mathrm{mm})^{2}$ & $42.03 \pm 1.07^{x}$ & $41.94 \pm 1.80$ & $40.65 \pm 1.51$ \\
\hline Nut width $(\mathrm{mm})^{\mathrm{z}}$ & $34.26 \pm 0.86$ & $33.20 \pm 1.42$ & $33.24 \pm 0.95$ \\
\hline Shell texture ${ }^{y}$ & Rough (7) & Smooth (3) & Rough (7) \\
\hline Shell color ${ }^{y}$ & Light (3) & Medium (5) & Light (3) \\
\hline Shell integrity ${ }^{y}$ & Intermediate (2) & Complete shell (3) & Intermediate (2) \\
\hline Nut, shape in longitudinal section perpendicular to suture ${ }^{z}$ & Triangular (2) & Ovate (4) & Triangular (2) \\
\hline Nut, shape in cross-section ${ }^{2}$ & Oblate (1) & Circular (2) & Oblate (1) \\
\hline Nut, shape of base perpendicular to suture ${ }^{z}$ & Truncate (3) & Rounded (2) & Truncate (3) \\
\hline Nut, shape of apex perpendicular to suture ${ }^{z}$ & Pointed (1) & Rounded (2) & Pointed (1) \\
\hline Nut, prominence of apical tip ${ }^{z}$ & Medium (5) & Weak (3) & Strong (7) \\
\hline Nut, position of pad on suture ${ }^{z}$ & On upper two-thirds of nut (2) & On upper half of nut (1) & On upper two-thirds of nut (2) \\
\hline Nut, prominence of pad on suture ${ }^{\mathrm{z}}$ & Strong (7) & Medium (5) & Strong (7) \\
\hline In shell nut weight $(\mathrm{g})^{\mathrm{y}}$ & $14.38 \pm 0.77$ & $13.68 \pm 1.25$ & $12.76 \pm 0.68$ \\
\hline Kernel weight $(\mathrm{g})^{\mathrm{y}}$ & $6.75 \pm 0.38$ & $6.81 \pm 0.73$ & $5.61 \pm 0.58$ \\
\hline Kernel percentage $(\%)^{y}$ & $46.92 \pm 0.82$ & $49.78 \pm 1.88$ & $43.92 \pm 2.99$ \\
\hline Kernel color ${ }^{y}$ & Light (3) & Extra light & Light (3) \\
\hline Kernel filly & Well (7) & Well (7) & Well (7) \\
\hline Ease of removal of kernel halves ${ }^{y}$ & Easy (3) & Very easy (1) & Easy (3) \\
\hline
\end{tabular}

${ }^{\mathrm{z}}$ When provided, numbers in parentheses refer to the descriptions according to the International Union for the Protection of New Varieties of Plants (1999) for walnut.

${ }^{\mathrm{y}}$ When provided, numbers in parentheses refer to the descriptions according to the International Plant Genetic Resources Institute (1994) for walnut.

${ }^{\mathrm{x}}$ Data are presented as mean $\pm \mathrm{SD}$. 


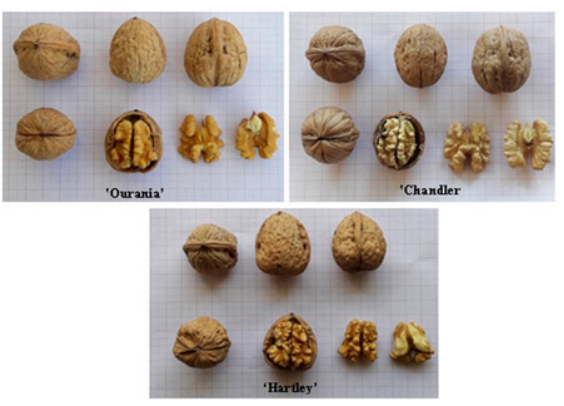

Supplemental Fig. 1. Nuts of 'Ourania', 'Chandler', and 'Hartley' walnut cultivars. 